Dossiê

\title{
A legitimidade das leis e das instituições de justiça na visão dos brasileiros
}

Fabiana Luci de Oliveira'

Luciana Gross Cunha ${ }^{2}$

Resumo: É senso comum afirmar que os brasileiros não respeitam as leis, e que no Brasil muitas leis são criadas, mas pouco obedecidas. Outra afirmação comum é que no país há "leis que pegam" e "leis que não pegam". A situação de baixa deferência à lei não seria típica apenas do Brasil, acontecendo em graus diferenciados ao redor do mundo, sendo que na América Latina haveria uma espécie de "cultura de desrespeito à lei", remontando à herança da colonização portuguesa e espanhola. Como consequência, o descumprimento da lei não seria visto como moral ou socialmente reprovável aqui. Com base nessas afirmações, poder-se-ia argumentar que no Brasil há um excesso de formalismo, com muitas regras que estabelecem padrões de comportamento, mas que, no dia a dia, não são levadas em conta pela população. Haveria, portanto, uma situação de desrespeito endêmico à lei. Nesse contexto, o objetivo do artigo é discutir e mensurar o comportamento do brasileiro com relação às normas, buscando responder o quanto e por que desobedecemos às leis. Dialogamos diretamente com o estudo de Tyler (2006), sobre o porquê de os americanos respeitarem as leis, testando o potencial explicativo das perspectivas normativa e instrumental no comportamento de obediência. Aqui, testamos essas duas perspectivas para explicar a desobediência. Concluímos que a perspectiva instrumental, que tem

\footnotetext{
1 Departamento e Programa de Pós-Graduação em Sociologia da UFSCar. - São Carlos - Brasil - Bolsista produtividade do CNPq. - fabianaluci@ufscar.br

2 Escola de Direito da FGV/SP - São Paulo - Brasil - luciana.cunha@fgv.br
} 
na dissuasão por sanções a melhor estratégia de combate à ilegalidade, não é adequada para explicar a desobediência às leis no Brasil, sendo os critérios propostos pela perspectiva normativa os que obtém maior potencial explicativo, 0 que incluiu a moralidade pessoal, a visão dos pares (controle social) e a confiança depositada na polícia e na honestidade da maioria dos juízes.

Palavras-chave: desobediência; legitimidade; moralidade pessoal; sanções; controle social.

\section{THE LEGITIMACY OF THE LAW AND THE JUSTICE INSTITUTIONS IN THE EYES OF THE BRAZILIAN PEOPLE}

Abstract: It is common sense to state that Brazilians do not respect the law, and that in Brazil many laws are enacted, but little obeyed. Another common assertion is that in Brazil there are "laws that stick" and "laws that do not stick". The situation of low deference to the law would not be typical only in Brazil, happening in different degrees around the world, being that in Latin America there would be a kind of "culture of disrespect to the law", going back to the inheritance of the Portuguese and Spanish colonization. As a consequence, noncompliance with the law would not be seen as morally or socially objectionable in the country. Based on these assertions, it could be argued that in Brazil there is an excess of formalism, with many rules that establish patterns of behavior, but that, day by day, are not taken into account by the population. There would be therefore a situation of endemic disrespect to the law. In this context, the goal of this paper is to discuss and measure the behavior of the Brazilian population regarding norms, seeking to answer how much and why we Brazilians disobey the law. We dialog directly with Tyler's (2006) study of why Americans respect the law, testing the explanatory potential of normative and instrumental perspectives on obedience behavior. We have tested these two perspectives to explain disobedience, concluding that the instrumental perspective, which has in deterrence by sanctions the best strategy to fight illegality, is not adequate to explain the disobedience to the law in Brazil, being the criteria proposed by the normative perspective the one obtaining greater explanatory potential, which included personal morality, peer evaluation (social control) and trust in the police and in honesty of judges.

Keywords: disobedience; legitimacy; personal morality; sanctions; social control. 


\section{Introduç̃̃̃o}

Um dos principais argumentos de Bobbio (1992) é de que não há democracia sem Direito, ou seja, não há democracia sem regras conhecidas e universais que organizem a sociedade e o governo, e condicionem o comportamento dos atores sociais. Quando as regras são devidamente observadas, há garantia de previsibilidade, estabilidade e segurança. Quando não são cumpridas, a democracia se fragiliza.

No Brasil não faltam regras. Uma pesquisa do Instituto Brasileiro de Planejamento e Tributação, ${ }^{3}$ publicada em 2015, mostra que desde a promulgação da Constituição de 1988 até setembro de 2015, mais de 5,2 milhões de normas haviam sido criadas, entre diplomas federais, estaduais e municipais, com uma média de 764 normas editadas por dia útil. E considerando apenas as normas federais, foram 161.582 nesse período - 23,5 normas editadas por dia útil, em média.

A existência de normas eficazes e legítimas é condição da existência de um Estado Democrático de Direito. Uma norma é eficaz quando é efetivamente cumprida, obedecida. E é legítima quando tem o respaldo da sociedade, na medida em que tenha se originado de um processo legislativo democrático (Habermas, 1997).

Jackson et al. (2011) afirmam que no paradigma weberiano, a legitimidade das leis implica que as pessoas veem o sistema legal (e as ordens emanadas de suas autoridades) como um padrão de conduta apropriado: a lei deve ser cumprida não por causa de uma sanção externa, mas porque é vista como o padrão correto. A legitimidade é conferida pelo cidadão. E no paradigma normativo de legitimidade há referência a aspectos substantivos do desempenho das autoridades e das normas, envolvendo "critérios mais objetivos" para a percepção de legitimidade, como eficiência, responsabilidade e legalidade (2011: 271-272).

O que as visões sobre eficácia e legitimidade colocam é que não basta existirem leis, é preciso garantir a sua aceitação e seu cumprimento. E o quanto as leis brasileiras têm sido cumpridas? E quão legítimas são aos olhos da população?

Há poucas evidências empíricas disponíveis para responder diretamente a esses questionamentos, mas é senso comum afirmar que nossas leis são pouco efetivas, e que existem leis que "pegam" e leis que "não pegam", virando "letra-morta”. A percepção geral é de que no país há baixo respaldo da sociedade às regras e às autoridades responsáveis pela sua aplicação, havendo, portanto, um problema de enforcement.

3 Pesquisa disponível em: <https://www.ibpt.com.br/img/uploads/novelty/estudo/2272/QuantidadeDeNormas 201527AnosCFo1102015.pdf>. Acesso em: 03 out. 2016. 28/12/2016. 
Os altos índices de criminalidade, a violência e a corrupção, noticiadas diariamente nas principais mídias do país, alimentam a sensação de que vivemos uma crise generalizada de desrespeito às leis e às instituições, e reforçam a tese de que no Brasil existe uma cultura endêmica de ilegalidade, um descumprimento sistemático das regras legais, nos termos de Garcia-Villegas (2009).

Na leitura de Roberto DaMatta (1997), a corrupção não é exclusividade do mundo político; ela seria uma característica inerente à formação do Brasil, remontando a processos históricos e culturais do Brasil colonial, constituindo uma sociedade profundamente hierarquizante, personalista e dual, em que operam duas categorias: a de indivíduo (em que as relações são regidas por leis impessoais, mas não como categoria universalizante, e sim como excludente, representando o "João-ninguém das massas") e a de pessoa (em que as relações são regidas pelo compadrio, pela amizade, troca de interesses e favores). Dessa dualidade adviria a oposição casa/rua, como espaços privilegiados onde indivíduo/ pessoa realizariam modalidades de relações sociais. Entre nós, brasileiros, predominariam, portanto, comportamentos orientados por padrões éticos flexíveis.

Segundo DaMatta (1986), no Brasil não se aplicaria a lei, mas sim a força das relações pessoais. Aqui a resolução dos conflitos seria informal, por meio de artifícios como a "carteirada", o "jeitinho" e a ameaça do "você sabe com quem está falando?".

Haveria assim, nessa colocação, um verdadeiro combate entre leis que devem valer para todos e relações que evidentemente só podem funcionar para quem as tem. (...) a malandragem, o "jeitinho" e o famoso e antipático "sabe com quem está falando?" seriam modos de enfrentar essas contradições e paradoxos de modo tipicamente brasileiro. Ou seja: fazendo uma mediação também pessoal entre a lei, a situação onde ela deveria aplicar-se e as pessoas nela implicadas, de tal sorte que nada se modifique, apenas ficando a lei um pouco desmoralizada - mas, como ela é insensível e não é gente como nós, todo mundo fica, como se diz, numa boa, e a vida retorna ao seu normal... (DaMatta, 1986: 64).

Mas é preciso ponderar, como faz Souza (2001), que a interpretação de DaMatta ignora a desigualdade socioecônomica e a divisão da sociedade em grupos e classes sociais. Para Da Matta, segundo Souza, há apenas indivíduos e espaços sociais. $\mathrm{O}$ autor critica, assim, a divisão casa/rua como artificial, afirmando que os grupos subalternos enfrentam situações de subcidadania independente do lugar ou espaço social onde estiverem. Souza (2001) critica, ainda, 
a interpretação de DaMatta da corrupção como um padrão cultural tradicional de personalismo herdado da colonização ibérica, apontando que faria mais sentido pensar que, se no Brasil ela fosse maior do que em outros países, isso poderia se dever à ausência de mecanismos mais eficazes de controle.

Nesse mesmo sentido, O'Donnell (1998b) nos mostra a importância do desenho institucional e da existência de instituições e controles capacitados, para que os princípios fundamentais do Estado de Direito - como universalidade das regras, transparência e imparcialidade no tratamento da lei - possam ser garantidos. Para o autor, além dessas garantias, é preciso olhar com atenção para os níveis de desigualdade social que, no caso do Brasil, criam obstáculos severos à grande parcela da sociedade no exercício de direitos, isso sem falar no impacto que produz na imparcialidade da lei (Vieira, 2007). Como pontua Souza (2001), a profunda desigualdade social brasileira é aspecto fundamental para compreender as relações dos brasileiros com a lei.

Dados da pesquisa ICJBrasil, da FGV Direito SP, ${ }^{4}$ realizada em junho de 2016, mostram que os baixos níveis de escolaridade também contribuem para o desconhecimento das leis: de acordo com a pesquisa, quase um terço dos brasileiros entrevistados não conheciam as leis do país, $61 \%$ conheciam pouco e apenas $9 \%$ conheciam bem nossas leis.

Observando o nível de conhecimento declarado de acordo com a escolaridade dos respondentes, percebemos que quanto maior a escolaridade, maior o conhecimento, com quase um terço dos brasileiros com alta escolaridade (superior completo) declarando conhecer bem as leis, comparados a apenas 5\% dos que têm baixa escolaridade (fundamental incompleto).

Apesar de desconhecerem as leis, $45 \%$ dos entrevistados acreditam que pessoalmente respeita muito as leis brasileiras. Outros $40 \%$ declararam que respeitam pouco as leis e $15 \%$ declararam não respeitar nada ou quase nada. E ao serem indagados sobre quem acreditam que mais desrespeita as leis no Brasil, $37 \%$ dos entrevistados responderam que a população em geral, $35 \%$ acreditam que os maiores descumpridores das leis são os deputados e senadores, outros 10\% acreditam que é o Presidente da República quem mais desrespeita as leis; $9 \%$ acreditam que são os policiais e $2 \%$ acreditam que os juízes são os que mais desrespeitam as leis no país.

Dado esse cenário, e as leituras sobre o perfil da sociedade brasileira em termos de respeito e legitimidade das leis, nosso objetivo nesse artigo é mensurar

4 Pesquisa disponível em: <http://bibliotecadigital.fgv.br/dspace/handle/10438/6618>. Acesso em: 04 out. 2017. 
e explicar o comportamento do brasileiro com relação às normas, discutindo o quanto e por que os brasileiros desrespeitam as leis.

Para isso, baseamo-nos no estudo de Tyler (Why People Obey the Law, 2006) sobre o porquê de os americanos respeitarem as leis. Tyler (2006) buscou compreender o comportamento cotidiano dos norte-americanos perante a lei, examinando o porquê de os cidadãos obedecerem ou desobedecerem as regras. Para identificar os determinantes do comportamento de obediência às leis, contrastou duas perspectivas: a instrumental e a normativa.

A perspectiva instrumental pressupõe que as pessoas são coagidas a seguir as regras, respondendo a incentivos e penalidades imediatamente tangíveis associados ao cumprimento da lei. Assim, é esperado que quanto maior a severidade das penas e as chances de punição, maior seja a probabilidade de cumprimento. A perspectiva normativa, por outro lado, está relacionada à percepção das pessoas sobre obrigação, moral e justiça, e sobre a legitimidade das autoridades legais. A internalização desses valores é que garantiria o cumprimento voluntário das leis.

Com base nessas perspectivas, o autor articulou quatro dimensões diferentes para explicar o grau em que as pessoas geralmente seguem a lei em suas vidas diárias: dissuasão (ameaça de sanções), opinião dos pares (controle social), moralidade pessoal (valores pessoais) e legitimidade (obrigação percebida de obedecer a lei e apoio às autoridades legais).

Tyler (2006) testou o efeito dessas dimensões na explicação do comportamento de obediência às leis a partir da realização de um survey (levantamento amostral) na cidade de Chicago. A principal conclusão do estudo é de que as pessoas obedecem à lei quando acreditam em sua legitimidade e na legitimidade das autoridades responsáveis pela sua aplicação, e não porque temem sanções.

Dialogamos diretamente com essa pesquisa para analisar o comportamento dos brasileiros com relação à legitimidade das leis e das instituições da justiça, utilizando, para isso, dados de um survey conduzido entre janeiro e julho de 2015, que entrevistou 3.300 brasileiros entre 18 e 70 anos de idade, residentes em oito unidades federativas (UF) brasileiras: Amazonas, Pernambuco, Bahia, Minas Gerais, Rio de Janeiro, São Paulo, Rio Grande do Sul e Distrito Federal. ${ }^{5}$

5 Os dados aqui analisados integram a pesquisa Índice de Percepção do Cumprimento da Lei, da Direito GV São Paulo. Para mais detalhes do desenho amostral, consultar o "Relatório IPCLBrasil - $1^{\circ}$ semestre/ 2015". Considerando que o survey entrevistou homens e mulheres, entre 18 e 70 anos de idade, residentes nas regiões metropolitanas de Amazonas, Pernambuco, Bahia, Minas Gerais, Rio de Janeiro, São Paulo, Rio Grande do Sul e Distrito Federal, a cobertura é de aproximadamente 60\% da população das regiões metropolitanas brasileiras, segundo dados do Censo 2010. A seleção dos entrevistados seguiu um 
$\mathrm{O}$ artigo que segue está organizado em três seções. Na primeira, "a cultura do desrespeito às leis na América Latina, traçamos a visão geral sobre a cultura de desrespeito à lei na região, a partir das leituras de Garcia-Villegas (2009; 2011) e Correa (2007).

Na segunda, "por que as pessoas obedecem as leis? O caso norte-americano", apresentamos o desenho do estudo de Tyler (2006), seus principais argumentos e conclusões.

Na terceira seção, "por que as pessoas desobedecem as leis? O caso brasileiro", apresentamos os resultados da pesquisa brasileira, concluindo no sentido de que a perspectiva instrumental, que tem na dissuasão por sanções a melhor estratégia de combate à ilegalidade, não é adequada para explicar a desobediência às leis no Brasil, sendo os fatores propostos pela perspectiva normativa os que obtém maior potencial explicativo, o que incluiu a moralidade pessoal, a visão dos pares (controle social) e a confiança depositada na polícia e na honestidade da maioria dos juízes. Ao contrário do que Tyler (2006) observou na pesquisa nos Estados Unidos, no Brasil, a percepção da obrigação internalizada de obediência à lei não teve efeito significativo no comportamento de desobediência às leis.

\section{A cultura do desrespeito às leis na América Latina}

A situação de baixa deferência à lei não seria típica apenas do Brasil, ela aconteceria em graus diferenciados ao redor do mundo, e particularmente de forma intensiva na América Latina.

De acordo com Garcia-Villegas (2009), na América Latina haveria uma espécie de cultura de desrespeito à lei, remontando à herança da colonização portuguesa e espanhola. E, como consequência, o descumprimento da lei não seria visto como moral ou socialmente reprovável. $\mathrm{O}$ autor vai à literatura e à linguagem popular para ilustrar como a cultura do desacato à lei é arraigada na América Latina, exemplificando com expressões brasileiras, como "manda quem pode, obedece quem quer", e a expressão que tem variantes por toda a região, "para meus inimigos a lei, para meus amigos tudo".

A proposta de Garcia-Villegas (2009; 2011) é entender a lacuna existente entre lei e realidade social na América Latina. $\mathrm{O}$ autor está interessado não em eventos flagrantes de violação, como assassinatos, roubos e corrupção política,

procedimento amostral por cotas, levando em conta o perfil da população das regiões metropolitanas das unidades federativas incluídas no estudo de acordo com sexo, idade, escolaridade, renda e condição de trabalho (PEA x Não PEA). Para mais detalhes da pesquisa e do desenho amostral consultar: <http:// hdl.handle.net/10438/14133>. Acesso em: 06 out. 2017. 
mas, sim, no desrespeito massivo e diário às leis, tidos como comportamentos padronizados e socialmente aceitos, numa espécie de desprezo pela legalidade.

En América Latina existe una enorme brecha entre, por un lado, las normas escritas, las que enseñan los profesores en las facultades de derecho, las que promulgan los legisladores y aplican los jueces y, por el otro, los comportamientos de la gente, incluyendo el de esos profesores y esos legisladores. Los latinoamericanos vivimos en una especie de sociedad esquizofrénica, en la que se habla mucho de lo que debe ser y se promulga mucho sobre el deber, pero se practica muy poco lo que se promulga. (Garcia-Villegas, 2011: 177)

$\mathrm{O}$ autor desenvolve um modelo típico-ideal do descumprimento das regras, afirmando que a cultura da violação das regras na América Latina poderia ser pensada a partir de três tipos (ou "mentalidades incumpridoras"). O primeiro é o "vivo", um ator racional, egoísta e utilitarista, que segue o ponto de vista estratégico, do cálculo de custos e benefícios da desobediência. O principal argumento aqui é de que os custos do descumprimento das leis são baixos comparados aos ganhos obtidos, e a falta de sanções eficazes seria um incentivo para a violação das regras. Como coloca Garcia-Villegas, "desobedecer às leis na América-Latina é barato" (2011: 166).

O segundo tipo é o "rebelde", um ator transgressor, que não reconhece a legitimidade das leis e das autoridades legais, considerando que os valores transmitidos por essas normas são menos importantes do que as regras do seu grupo social.

O terceiro tipo ideal é o "arrogante", um ator elitista que acredita estar acima da leis, devido à sua posição na hierarquia social. O arrogante de Garcia-Villegas aproxima-se do mecanismo do "você sabe com quem está falando?", de DaMatta (2002).

Como tipos-ideias que são, essas três mentalidades se mesclam, gerando tipos híbridos, como o "déspota", combinando a estratégia do vivo com a arrogância, própria dos “donos do poder", e o tipo "astuto", numa mistura da visão estratégica com a rebeldia, tática de resistência velada dos subordinados.

Correa (2007) também aborda a questão da cultura do desrespeito às leis na América Latina, abordando o caso do México. A autora discute como nesse país as leis são vistas como iníquas pela maioria da população, com o seu cumprimento sendo visto como necessário apenas na medida em que não pode ser evitado. Correa (2007) apresenta dados de um survey nacional conduzido no México no ano de 2002, no qual $71 \%$ dos entrevistados declararam acreditar que as pessoas não devam obedecer leis que lhes pareçam injustas, e $45 \%$ 
declararam que nem os cidadãos nem as autoridades respeitavam as leis no país. Recorrendo à pesquisa de opinião pública Latinobarômetro, de 2004, vemos que $75 \%$ dos mexicanos acreditavam que o país era governado por interesses de poucos poderosos pensando em seu benefício próprio, e não governado para o bem de toda a população (2007: 4). Observando os dados dessa pesquisa para o Brasil, temos que em 2004, 69\% dos brasileiros entrevistados declararam acreditar que o país era governado em benefício de interesses de poucos poderosos, e $31 \%$ acreditavam que o país era governado em benefício do interesse da maioria da população. ${ }^{6}$

A autora chama de "narrativas de desconfiança" a descrença dos mexicanos nas leis e nas instituições jurídicas, argumentando que o discurso de desrespeito é comum também entre autoridades políticas do país, citando o exemplo de López Obrador ao ser derrotado nas eleições presidenciais de 2006 e questionar a lisura do processo. Segundo Correa (2007), o discurso de Obrador sintetizaria o sentimento comum dos mexicanos em relação ao governo, às autoridades e às instituições, de que eles serveriam para promover os interesses dos mais fortes e poderosos em detrimento dos interesses do povo.

Assim, Correa afirma a existência de uma cultura endêmica de ilegalidade no México, que se evidenciaria desde as práticas cotidianas dos cidadãos, às narrativas públicas das elites políticas. E isso alimentaria a desconfiança com relação às autoridades legais, ao direito e suas instituições.

Neste artigo, nosso interesse está em verificar empiricamente a existência de uma cultura endêmica de ilegalidade no Brasil, a partir da percepção dos brasileiros sobre o desrespeito às leis no país, com foco em suas práticas cotidianas.

\section{Por que as pessoas obedecem as leis? 0 caso norte-americano}

Tyler abre seu estudo afirmando que "Os americanos são tipicamente pessoas que cumprem as leis" (2006: 3), mas que, apesar disso, a conformidade com a lei nunca é completa. Para colocar uma métrica no nível de cumprimento das leis, opta pela autodeclaração de comportamento, com base em um survey conduzido com uma amostra aleatória de 1.575 moradores de Chicago, no ano de 1984 - sendo que 804 pessoas selecionadas aleatoriamente a partir dessa primeira amostra foram entrevistadas novamente em 1985, perfazendo duas ondas do estudo.

6 Os dados do Latinobarômetro estão disponíveis em: <http://www.latinobarometro.org/lat.jsp >. Acesso em: 06 out. 2017 . 
O autor afirma que apesar de ser mais provável as pessoas relatarem práticas de ofensas menos sérias do ponto de vista legal, considera a autodeclaração apropriada para verificar adesão às normas, sendo este o método mais frequentemente utilizado para avaliar o desrespeito à lei, havendo estudos que demonstram aproximação de resultados do autorelato com os registros policiais de violação das normas (Tyler, 2006: 40).

Para representar o espectro de normas com o qual as pessoas lidam cotidianamente, Tyler elegeu seis infrações, com diferentes níveis de potencial ofensivo, e averiguou o comportamento dos entrevistados, utilizando uma escala de cinco pontos (nunca, quase nunca, poucas vezes, algumas vezes, muitas vezes), para contabilizar a frequência com que engajaram em cada um dos comportamentos (ver Gráfico 1).

Gráfico 1. Percentual de entrevistados que declararam desrespeitar a lei em Chicago

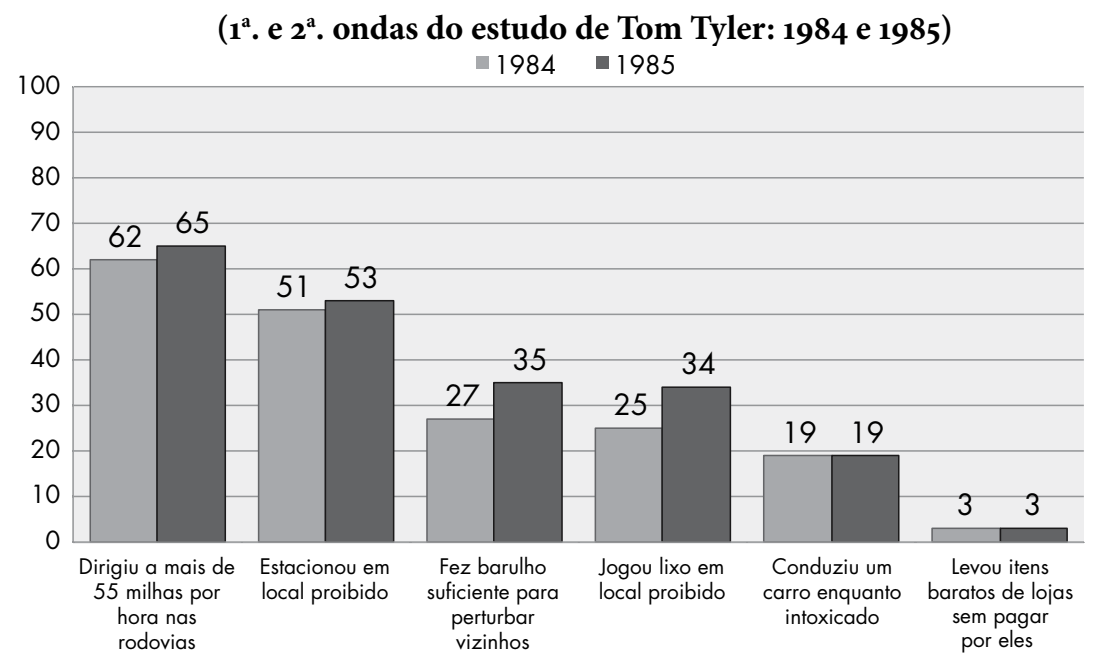

Fonte: construído com base em Tyler (2006,: 41-43)

Considerando os que declararam já ter praticado a infração alguma vez (ou seja, responderam quase nunca, poucas vezes, algumas vezes ou muitas vezes), temos que os comportamentos mais frequentes foram os de dirigir acima da velocidade permitida e estacionar em local proibido, com a maioria dos entrevistados (65\% e 53\%, respectivamente) declarando ter engajado nesse comportamento alguma vez. Com base nessas respostas, Tyler construiu um indicador de cumprimento da lei (compliance with the law).

Para mensurar a percepção das perdas associadas ao descumprimento da lei, o autor perguntou aos entrevistados, para cada uma das seis infrações, o 
quão provável achavam que seriam presos ou multados caso praticassem esses atos, numa escala de intensidade de quatro pontos, sendo: muito provável, um pouco provável, um pouco improvável ou muito improvável. Com base nas respostas, construiu um indicador de dissuasão por sanções (deterrence).

Com relação à percepção de reprovação social, solicitou aos entrevistados que pensassem nos cinco adultos que melhor conheciam e considerassem o quanto eles desaprovariam a conduta dos entrevistados caso esses fossem pegos pelo comportamento de descumprimento da lei em cada uma das seis situações, utilizando a mesma escala de quatro pontos de probabilidade, e com isso criou um indicador de reprovação dos pares (peer disapproval).

Para capturar a percepção dos entrevistados sobre o quão certo ou errado é descumprir as leis, solicitou a eles que considerassem seus próprios sentimentos sobre o que é certo e errado e avaliassem o quão errado acreditavam que seria se envolver em cada uma das seis situações apresentadas, utilizando uma escala de 4 pontos: muito errado, um pouco errado, não muito errado ou nada errado. Com base nas respostas, construiu um indicador de moralidade pessoal.

Por fim, para mensurar a legitimidade, trabalhou de duas formas: avaliando as autoridades legais (policiais e juízes) e o sentimento de dever de obediência às leis.

Sobre as autoridades, apresenta questões sobre a percepção de sua atuação, entre as quais a avaliação sobre sua honestidade. Ao indagar o quanto concordavam ou discordavam que "em geral, os policiais de Chicago são honestos", $64 \%$ dos entrevistados declararam concordar ou concordar muito. E repetindo a mesma pergunta para os juízes de Chicago, $62 \%$ dos entrevistados declararam concordar ou concordar muito que eles eram honestos.

Para colocar uma métrica no dever de obediência, Tyler (2006) inicia a entrevista afirmando que as pessoas têm diferentes opiniões sobre a importância de obedecer à lei e às ordens de juízes e policiais, e então solicita que o entrevistado considere seu próprio sentimento com relação a isso e responda o quanto concorda ou discorda de cada uma das seis frases (ver Gráfico 2).

Os resultados mostraram que a percepção do dever de obediência é elevado, com a maioria dos entrevistados concordando com todas as afirmações. É notável que a percepção de dever de obediência aos policiais é superior à percepção do dever de obediência aos juízes. E o que gerou maior discordância foi a afirmação de que "é difícil desrespeitar a lei e manter o autorespeito". As respostas a essas perguntas deram origem ao indicador de legitimidade. 
Gráfico 2. Percentual de entrevistados que declararam concordar com afirmações

(1a. onda do estudo de Tom Tyler 1984)

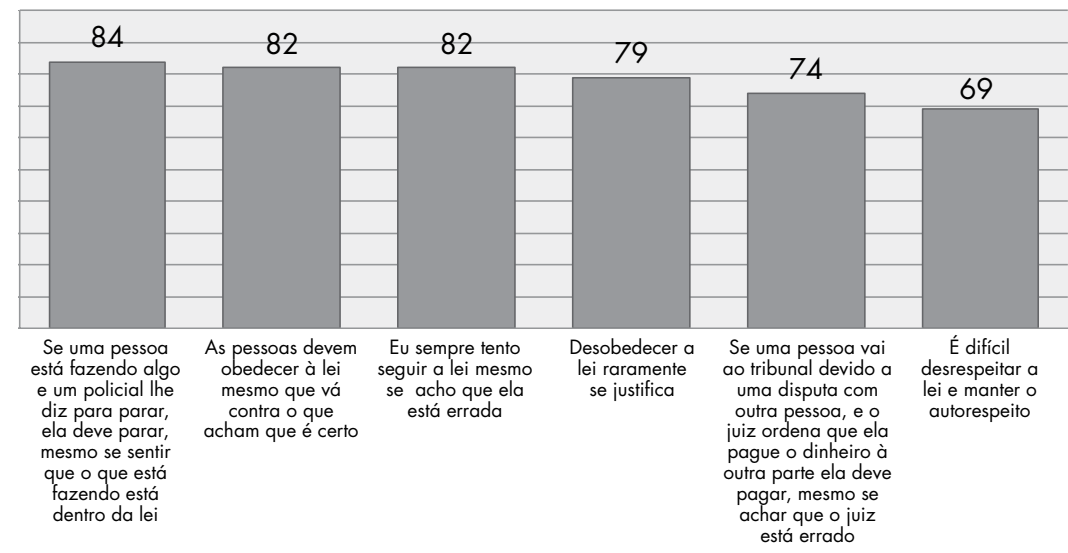

Fonte: construído com base em Tyler (2006: 45)

Tyler (2006) modelou o impacto de cada um desses indicadores no comportamento de obediência às leis, e concluiu que a legitimidade desempenha um importante papel na promoção da obediência às leis, mas que a moralidade pessoal e a desaprovação dos pares são influências mais determinantes. Encontra influência também do sexo e da idade dos respondentes, sendo que as mulheres e as pessoas mais velhas têm maior probabilidade de seguir as leis.

Embora encontre correlação positiva entre os indicadores de cumprimento das leis e de dissuasão por sanções $(0,22)$, quando todos os indicadores são levados em conta conjuntamente num modelo de regressão, a dissuasão perde significância estatística.

Ou seja, o problema da desobediência não se resolve com coerção e punição, uma vez que a adesão às regras está mais relacionada com o reconhecimento da legitimidade das leis e das autoridades legais do que com o receio de sanções.

Uma das principais contribuições do estudo de Tyler é, portanto, mostrar que políticas públicas de segurança ortodoxas que costumam se basear no aumento da severidade de sanções e promover maior "punitivismo" no combate à criminalidade são mais custosas ao Estado e não alcançam os objetivos almejados, uma vez que mais do que temor das sanções, o respeito às leis se baseia em julgamentos de moralidade pessoal, na cultura de pares e na legitimidade das autoridades.

\section{Por que as pessoas desobedecem as leis? 0 caso brasileiro}

Ao contrário do norte-americano, que é visto como cumpridor das leis, o brasileiro é tido como descumpridor costumaz. Por isso, nosso interesse aqui é entender o quanto e por que os brasileiros desrespeitam as leis. Partimos do 
estudo de Tyler (2006), mas realizamos adaptações, levando em conta tanto o contexto sociocultural e institucional brasileiro, quanto a distância no tempo com relação ao survey de Chicago.

Assim, nossa intenção não é comparativa, mas, sim, de nos basearmos no modelo teórico e empírico do autor para medir, de forma sistemática, a percepção dos brasileiros com relação ao desrespeito às leis e às determinações das autoridades legais diretamente envolvidas com o seu cumprimento: policiais e juízes.

$\mathrm{O}$ argumento principal do estudo de Tyler (2006) é o de que as pessoas obedecem à lei quando acreditam que ela é legítima e não porque temem sanções. Testamos o mesmo argumento no Brasil, baseando-nos em cinco indicadores principais: (i) comportamento, que retrata a frequência com que os entrevistados declararam engajar em desobediência às leis; (ii) instrumentalidade, mensurando a percepção de perdas associadas ao descumprimento das leis, especificamente em relação à probabilidade de punição; (iii) moralidade pessoal, medindo a percepção de quanto é certo ou errado engajar-se em condutas de desobediência às leis; (iv) controle social, retratando a percepção de desaprovação social pelos pares de comportamentos de desobediência às leis e (v) legitimidade, que mensura a percepção de obrigatoriedade internalizada de respeito à lei e obediência às autoridades legais.

Compreender por que as pessoas cumprem ou não a lei contribui não só para avaliar as possibilidades e os limites das soluções jurídicas aos problemas sociais e econômicos brasileiros, mas também para pensar políticas públicas mais adequadas às soluções desses problemas. Assim, compreendendo o que explica a desobediência, é possível melhor orientar práticas de incentivo e adesão às regras.

A variável dependente do nosso estudo é o comportamento de desobediência, que foi mensurado a partir da frequência com que os entrevistados relataram ter realizado ações que de alguma forma representam desrespeito à lei.

Partimos de dez infrações cotidianas que representam diferentes graus de potencial ofensivo (ver Gráfico 3), para as quais os entrevistados declararam a frequência com que as realizaram nos últimos 12 meses, a partir de uma escala de intensidade de cinco pontos: nunca, quase nunca, poucas vezes, algumas vezes ou muitas vezes.

É evidente que não esperamos que esse indicador seja preciso, uma vez que há o viés de desejabilidade social, já apontado por Tyler (2006), sendo os entrevistados mais propensos a admitirem ofensas percebidas como de menor gravidade. Assim como na pesquisa de Tyler, da década de 1980, na pesquisa brasileira de 2015 poucas pessoas declararam ter levado itens de uma loja sem pagar por eles - $3 \%$ lá e $4 \%$ aqui.

No estudo brasileiro foram utilizadas cinco das infrações trabalhadas na pesquisa de Chicago, e outras cinco tidas como práticas comuns no Brasil. E justamente duas dessas práticas foram as situações mais corriqueiras de desrespeito à lei admitidas pelos entrevistados: atravessar a rua fora da faixa de pedestre 
(70\% declararam ter feito isso alguma vez nos 12 meses anteriores à data da entrevista) e comprar produtos piratas (60\% dos entrevistados o admitiram).

Cerca de um quarto dos entrevistados declararam ter estacionado em local proibido (considerando apenas os entrevistados que dirigem, temos $38 \%$ dos motoristas declarando desrespeito a essa lei). Dirigir depois de beber foi admitido por $17 \%$ do total de entrevistados (considerando apenas os que dirigem, $27 \%$ dos motoristas declararam desrespeito a essa lei). Fumar em local não permitido foi reconhecido por $12 \%$ deles (considerando apenas os que fumam, $47 \%$ dos fumantes declararam desobediência a essa lei).

Fazer barulho capaz de incomodar os vizinhos foi declarado por $37 \%$ dos entrevistados; jogar lixo em local proibido, por $27 \%$; utilizar carteira falsa de estudante para pagar meia entrada foi admitido por $9 \%$ dos entrevistados.

A corrupção foi abordada aqui a partir da oferta de dinheiro à autoridade para evitar ser multado, prática a qual 5\% dos entrevistados admitiram ter aderido nos 12 meses anteriores à entrevista.

Com base nessas dez ações, construímos um indicador de desrespeito às leis que varia de o (declarou nunca para todas as dez infrações) a 10 (declarou muitas vezes para todas as dez infrações). A média observada ficou em 1,6 pontos, com $25 \%$ dos entrevistados pontuando até 0,75 (os $25 \%$ menos desobedientes), metade pontuando até 1,25 e $75 \%$ pontuando até 2,25 .

Apenas 13\% dos entrevistados não pontuaram, ou seja, declararam nunca terem se envolvido em nenhuma das ações de desobediência às leis investigadas no estudo, e menos de $1 \%$ declarou ter realizado muitas vezes todas as infrações.

Nosso interesse está em entender o que explica o comportamento de desobediência às leis. Para isso, consideramos o modelo proposto por Tyler (2006), testando o impacto que a dissuasão por sanções tem no comportamento de desobediência frente a outros fatores, como moralidade pessoal, legitimidade da lei e das autoridades legais e opinião dos pares.

Para mensurar a dissuasão por sanções, construímos um indicador de instrumentalidade, baseado na resposta dada pelos entrevistados sobre sua percepção da probabilidade de serem punidos caso cometessem cada uma das dez infrações, sendo a escala de resposta: muito provável, um pouco provável, um pouco improvável ou muito improvável - o indicador varia de o (consideram muito improvável a punição para as dez infrações) a 10 (consideram muito provável punição para as dez infrações). A média do indicador de instrumentalidade é 5,7 pontos, com mediana 6 e desvio-padrão 2,6. Ou seja, em geral, os brasileiros consideram pouco efetivas as chances de sofrerem sanções.

De forma genérica, existe uma correspondência inversa entre o comportamento de desobediência e a percepção de risco de sanção, ou seja, as infrações pelas quais as 
pessoas acham mais provável serem punidas, são as que foram menos realizadas, com exceção de fumar em local proibido, utilizar falsa carteira de estudante para pagar meia entrada ou obter descontos e pagar "propina" a autoridades para não ser multado.

As duas infrações vistas com maior risco de punição são as de furto (levar itens baratos de uma loja sem pagar por eles) e de dirigir alcoolizado - são as únicas para as quais a maioria dos entrevistados acredita haver maior probabilidade de sanção efetiva.

No que se refere à moralidade pessoal, trabalhamos a partir do sentimento declarado sobre o quão certo ou errado os entrevistados acreditam serem os comportamentos listados nas dez infrações, classificando as respostas numa escala de intensidade de quatro pontos: muito errado, um pouco errado, quase nada errado ou nada errado. A maioria dos entrevistados acredita que todas as situações são muito erradas, sendo que a quase totalidade deles (94\%) afirmaram ser muito errado dirigir embriagado e furtar itens baratos de lojas. $\mathrm{O}$ indicador de moralidade pessoal varia de o (considerando as 10 infrações nada erradas) a 10 (considerando as 10 infrações muito erradas). A média do indicador de moralidade pessoal é de 9 pontos, com mediana de 9,3, e desvio-padrão de 1,4 pontos, indicando um alto sentimento de dever pessoal de seguir as leis.

Gráfico 3. Indicadores de desobediência às leis (\%)

Base: 3.300 entrevistas

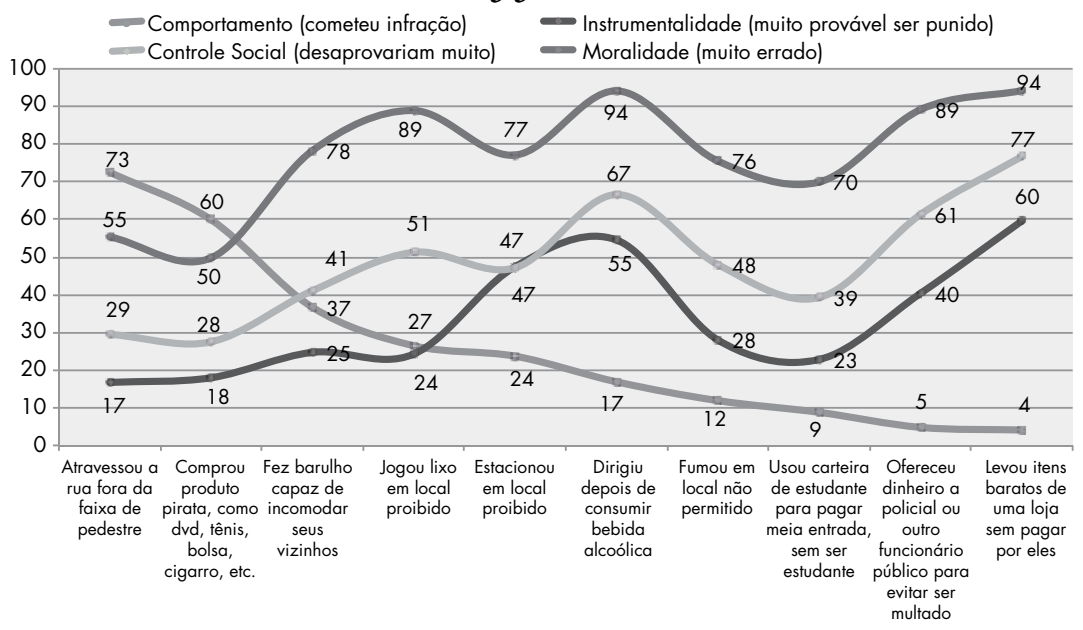

Fonte: Construído com base em IPCLBrasil, FGV Direito SP, 2015

O indicador de controle social foi construído a partir da resposta dos entrevistados acerca da percepção de desaprovação dos amigos e familiares próximos, na hipótese de serem vistos cometendo cada uma das dez infrações citadas, sendo as possibilidades de resposta: desaprovariam muito, desaprovariam um pouco, quase nada ou nada. 
Apenas quatro das condutas foram percebidas como recebendo grande desaprovação dos pares: furtar itens baratos de lojas ( $77 \%$ acreditam que amigos e familiares próximos reprovariam muito essa ação), dirigir depois de beber ( $67 \%$ de reprovação); oferecer dinheiro a policiais ou autoridades para escapar de multa (61\% de alta reprovação) e jogar lixo em local proibido (51\% de reprovação). O consumo de produtos piratas é visto como a infração menos recriminada pelos pares.

Com base nessas respostas, construímos o indicador de controle social que varia de o (responderam para as 10 infrações que amigos e familiares próximos não desaprovariam nada) a 10 (responderam que desaprovariam muito para todas as 10 situações). A média do indicador foi de 7 , com mediana 7,7, e desvio-padrão de 2,6 pontos, indicando um moderado grau de controle social.

Por último, mas não menos importante, trabalhamos com um indicador de legitimidade, mensurando a percepção de internalização da obrigação de obediência à lei. A construção do indicador se baseou nas declarações do nível de concordância com cinco frases (ver Gráfico 4), sendo as respostas possíveis: concorda totalmente, concorda em parte, discorda em parte ou discorda totalmente.

O maior nível de concordância apresentado foi com relação ao dever de obedecer uma ordem judicial: $77 \%$ declararam concordar em ter que segui-la mesmo discordando do conteúdo. Em segundo lugar, 73\% declararam concordar em ter que seguir as leis ainda que ela vá contra sua crença pessoal no que é certo. Ao mesmo tempo, a maioria (56\%) declarou concordar existirem poucas razões para uma pessoa seguir as leis no país, e 54\% declararam que raramente é justificável desrespeitar as leis. No que se refere à autoridade policial, a maioria dos entrevistados não considera necessário obedecer uma ordem policial caso discordem dessa ordem.

Gráfico 4. Indicador de legitimidade (\% que concorda com afirmações)

\section{Base: 3.300 entrevistas}

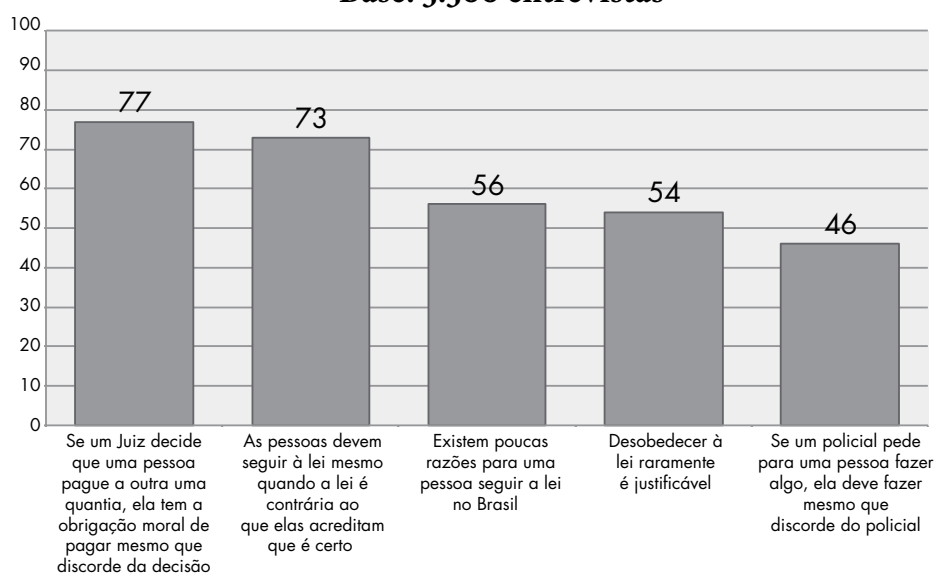

Fonte: Construído com base em IPCLBrasil, FGV Direito SP, 2015 
Com base nessas respostas, construímos o indicador de legitimidade, variando de o (concorda muito que "existem poucas razões para uma pessoa seguir a lei no Brasil", e discorda muito das demais afirmações) a 10 (discorda muito que "existem poucas razões para uma pessoa seguir a lei no Brasil", e concorda muito com as demais afirmações). A média do indicador de legitimidade é de 5,8 pontos, com mediana 6 e desvio-padrão de 1,8, apontando para a baixa internalização geral do dever de obediência.

Observando a relação desses quatro indicadores com o indicador de desobediência, todos apresentam uma correlação negativa significativa, ou seja, quanto maior a legitimidade $(r=-0,05$, sig. 0,01$)$, o receio de sanção $(r=-0,17$, sig. $0,01)$, o controle social pelos pares $(r=-0,29$, sig. 0,01$)$ e o sentimento de moralidade pessoal ( $\mathrm{r}=-0,34$, sig. 0,01), menor a desobediência.

Mas qual o efeito desses quatro indicadores no comportamento de desobediência quando considerados em conjunto? Para testar a contribuição independente de cada um desses indicadores na explicação do comportamento de desobediência, utilizamos um modelo de regressão linear.

Utilizamos como variáveis preditoras em nosso modelo, além dos quatro indicadores de instrumentalidade, controle social, moralidade pessoal e legitimidade, variáveis socioeconômicas e demográficas: cor ou raça do entrevistado (considerando como categoria de referência os brancos), o estado civil do respondente (considerando como categoria de referência os casados), sexo (considerando como como categoria de referência as mulheres), a idade dos respondentes em anos completos, o nível de escolaridade (anos completos de escolaridade), o nível de renda (em salários mínimos) e a situação no mercado de trabalho (se é população economicamente ativa).

Além disso, levamos também em conta a confiança declarada na Polícia e no Poder Judiciário e a percepção sobre a honestidade da maioria dos policiais e da maioria dos juízes.

E uma vez que as teorias econômicas consideram o comportamento de cooperação como determinante para o respeito às regras, utilizamos um proxy para esse perfil. Nessa perspectiva, as pessoas obedecem a lei na medida em que percebem que os outros no seu entorno também estão obedecendo, e deixam de obedecer caso percebam que os outros estão desobedecendo, deixando, portanto, de cooperar. Segundo Correa (2007), as teorias econômicas do comportamento compreendem que as pessoas tendem a agir de acordo com o padrão de comportamento percebido no resto dos indivíduos de seu segmento social, independentemente dos incentivos existentes. 
Construímos um indicador para capturar a percepção de cooperação a partir do nível de concordância que os entrevistados declararam à frase "sempre que possível as pessoas escolhem dar um 'jeitinho' em vez de seguir a lei” - considerando que quanto maior a concordância, menor a percepção de cooperação.

A maioria dos entrevistados declarou concordar muito com a afirmação (54\%), sendo que $26 \%$ declararam concordar um pouco, $8 \%$ declararam discordar um pouco e $9 \%$ discordar muito. Cerca de $2 \%$ dos entrevistados não souberam responder. Portanto, o nível de cooperação percebido é baixo, o que vai ao encontro das pesquisas sobre confiança, mostrando que os brasileiros apresentam baixa confiança interpessoal (ver Moisés, 2010).

De acordo com os resultados do nosso modelo (ver Tabela 1), a variável de maior efeito na chance de desobediência às leis é o indicador de moralidade pessoal, sendo que conforme ele aumenta, diminui a chance de desobediência. Em segundo lugar, o aumento da idade contribui para a redução da desobediência. E em terceiro lugar, o indicador de controle social também contribui na redução das chances de desrespeitar as leis, com o sexo tendo o mesmo efeito, sendo que as mulheres apresentam chances menores do que os homens de desrespeitar as leis.

Os indicadores de legitimidade e instrumentalidade não obtiveram significância estatística. Ou seja, nem a percepção de internalização da obrigação de obediência à lei, nem o medo de sofrer sanções influenciaram nas chances de desobediência. Isso implica que, no Brasil, assim como nos EUA, políticas de combate à ilegalidade que apostam na dissuasão e no aumento da severidade das penas não obtém o sucesso esperado. Os resultados são um indicativo de que o medo de sofrer sanções não é o principal incentivo para adesão às leis, mas mais do que a legitimidade, é a moralidade pessoal que mais influencia no comportamento de cumprimento das regras.

Mas a percepção de legitimidade das autoridades legais exerce influência independente na explicação do comportamento de desobediência. Tanto a confiança na Polícia, quanto a percepção de honestidade dos juízes contribuem para a redução da desobediência - efeitos estatisticamente significativos, embora pequenos. A confiança no Poder Judiciário e a percepção de honestidade dos policiais não obtiveram efeitos estatisticamente significativos.

Tabela 1. Modelo de regressão (linear), considerando como variável alvo o indicador de desobediência*

\begin{tabular}{|l|c|c|c|}
\hline & Beta & Sig. & Correlação \\
\hline Indicador de instrumentalidade & $-0,02$ & 0,39 & $-0,15$ \\
\hline Indicador de controle social & $-0,13$ & 0,00 & $-0,28$ \\
\hline
\end{tabular}


(continuação)

\begin{tabular}{|l|c|c|c|}
\hline Indicador de moralidade pessoal & $-0,22$ & 0,00 & $-0,32$ \\
\hline Indicador de legitimidade & $-0,02$ & 0,28 & $-0,05$ \\
\hline Confiança no Judiciário & $-0,01$ & 0,71 & $-0,07$ \\
\hline Honestidade dos juízes & $-0,08$ & 0,00 & $-0,15$ \\
\hline Confiança na Polícia & $-0,07$ & 0,00 & $-0,13$ \\
\hline Honestidade dos policiais & 0,01 & 0,81 & $-0,13$ \\
\hline Cooperação & $-0,01$ & 0,98 & $-0,04$ \\
\hline Cor ou raça (branco) & $-0,06$ & 0,00 & $-0,07$ \\
\hline Estado civil (casado) & $-0,01$ & 0,81 & $-0,07$ \\
\hline Sexo (feminino) & $-0,13$ & 0,00 & $-0,16$ \\
\hline Idade & $-0,14$ & 0,00 & $-0,25$ \\
\hline Escolaridade (anos de escolaridade) & $-0,01$ & 0,69 & 0,08 \\
\hline Renda Familiar (salários mínimos) & 0,06 & 0,01 & 0,10 \\
\hline PEA & 0,04 & 0,07 & 0,14 \\
\hline
\end{tabular}

${ }^{*}$ Média $=1,6$ e desvio-padrão $=1,4$

$\mathrm{R}^{2}$ (ajustado) $=20 \%$

Número de observações: 2.382

Cor ou raça também está associada às chances de desobediência, com os brancos tendo menores chances de desobedecer às leis comparados aos não brancos. Esse mesmo efeito foi observado no estudo de Tyler (2006: 59). Isso pode ser explicado pelo fato de que aqui, assim como nos Estados Unidos, os não brancos, sobretudo os negros, são os mais vulneráveis frente às leis e às autoridades legais.

As estatísticas nacionais comprovam que os negros encontram-se em piores condições socioeconômicas, são sistematicamente mais abordados pela polícia e constituem a maioria da população privada de liberdade (BRASIL, 2015). Sua posição de maior vulnerabilidade também pode ajudar a explicar sua maior desconfiança das instituições e das autoridades legais e, portanto, as maiores chances de desobediência de leis que sistematicamente os penalizam mais.

Outro fator que impacta na desobediência é a renda, sendo que o aumento da renda contribui para o aumento da desobediência às leis. O que reforça a percepção corriqueira de que a lei se aplica em graus diferenciados a ricos e pobres no país.

Esperávamos que escolaridade e o indicador de cooperação tivessem também um impacto negativo no nível de desobediência, mas não foram encontrados resultados estatisticamente significativos. 


\section{Considerações finais - um dilema de legitimidade?}

A legitimidade das regras que organizam a sociedade e das autoridades responsáveis pelo cumprimento dessas regras são pilares essenciais do Estado Democrático de Direito. Em países com alta concentração de renda e grau de pobreza considerável, como é o caso do Brasil, os critérios que organizam essa legitimidade são afetados de formas não ainda completamente mensuráveis. De acordo com Vieira (2007), um dos efeitos da desigualdade de renda e da consequente exclusão social e econômica no Estado de direito, é a destruição da imparcialidade da lei, "causando a invisibilidade dos extremamente pobres, a demonização daqueles que desafiam o sistema e a imunidade dos privilegiados, aos olhos dos indivíduos e das instituições" (Vieira, 2007: 29).

Contribuindo para esse diagnóstico, os resultados apresentados nesse artigo mostram que, no Brasil, assim como nos Estados Unidos, a partir da pesquisa orientada por Tom Tyler (2006), o respeito às regras não pode ser explicado exclusivamente pela perspectiva instrumental, ou seja, pela existência ou não de sanção, ou mesmo pelo grau de severidade dessa sanção. Existe uma lacuna entre a lei e a realidade que deve ser levada em conta. Nesse sentido, o contexto no qual o respeito às regras e à legitimidade das autoridades operam é essencial para entendermos esse fenômeno. É por isso que as variáveis de moralidade pessoal, visão dos pares, confiança na Justiça e percepção de honestidade dos juízes importam para a adesão às regras.

Quando 40\% dos entrevistados afirmam que respeitam pouco as leis, o ambiente para que haja obediência às leis não parece propício. Se acrescentarmos a esse dado o fato de que $56 \%$ dos entrevistados concordam com a afirmação de que "existem poucas razões para seguir as leis no Brasil" e de que $54 \%$ concordam que "sempre que possível, as pessoas escolhem dar um 'jeitinho' em vez de seguir a lei", não parece que o desenho institucional seja capaz de, sozinho, explicar o funcionamento do Estado de direito.

Comparando os dados da pesquisa brasileira com o survey coordenado por Tyler (2006), na cidade de Chicago, o que mais chama a atenção é a diferença no reconhecimento da legitimidade de policiais, nos dois países. Nos Estados Unidos, $84 \%$ dos entrevistados disseram concordar com a afirmação "se uma pessoa está fazendo algo e um policial lhe diz para parar, ela deve parar, mesmo se sentir que o que está fazendo está dentro da lei". No Brasil, para uma situação equivalente, o número de entrevistados que concordaram com a mesma afirmação foi de $46 \%$. Essa diferença não aparece quando a ordem é dada por um juiz: nos Estados Unidos, 74\% dos entrevistados disseram reconhecer a autoridade do juiz; no Brasil, $77 \%$ dos entrevistados disseram concordar com a afirmação 
"se um juiz decide que uma pessoa pague a outra uma quantia, ela tem a obrigação moral de pagar mesmo que discorde da decisão".

Esses números mostram que, diferente do que propõe a literatura de viés culturalista, que busca explicações para as falhas no Estado de Direito na história e na cultura de cada país, outros fatores também podem influenciar a legitimidade das regras que compõem o Estado de Direito e fazem dele uma situação de fato. Isso talvez mostre o dilema da legitimidade no caso brasileiro. Ainda seguindo essa linha, o status do Estado de Direito e, particularmente, a relação entre o cidadão, as regras e as autoridades, talvez esteja mais relacionada às desigualdades sociais e econômicas e daí a nossa aproximação com o comportamento do norte-americano, no que diz respeito ao trabalho de Tyler (1998) ${ }^{7}$

Os dados apresentados aqui indicam que a explicação para a desobediência às leis no Brasil passa pelo conjunto de indicadores de moralidade pessoal, que predizem a obediência às regras a partir da avaliação individual de cada entrevistado, acerca do que é certo e do que é errado, contribuindo também para a compreensão desse fenômeno indicadores socioeconômicos de cor/raça e renda, que, por sua vez, corroboram o argumento de que desigualdade social e econômica e alta concentração de renda afetam o Estado de Direito.

\section{Referências}

BOBBIO, Norberto. A era dos direitos. 11. ed. Rio de Janeiro: Campus, 1992.

BRASIL. Presidência da República. Secretaria Geral. Mapa do encarceramento: os jovens do Brasil / Secretaria-Geral da Presidência da República e Secretaria Nacional de Juventude. - Brasília : Presidência da República, 2015. 112 p.: il. - (Série Juventude Viva). Dísponível em: <http://juventude.gov.br/articles/participatorio/oo10/1092/ Mapa_do_Encarceramento_-_Os_jovens_do_brasil.pdf $>$. Acesso em: 06 out. 2017. CORREA, Catalina Perez. "Distrust and Disobedience: Discourse and Practice of Law in México". SELA (Seminario en Latinoamérica de Teoría Constitucional y Política) Papers. Paper 52, 2007 Disponível em: <http://digitalcommons.law.yale.edu/yls_ sela/52/>. Acesso em: 06 out. 2017.

DAMATTA, Roberto. O que faz o brasil, Brasil? Rio de Janeiro: Rocco, 1986.

Carnavais, Malandros e Heróis: para uma sociologia do dilema brasileiro. $6^{\text {a }}$. Edição. Rio de Janeiro: Rocco, 1997.

7 Se verificarmos o Índice de Desenvolvimento Humano Ajustado à Desigualdade (IDHAD), percebemos o quanto a desigualdade social e econômica dos Estados Unidos é próxima à nossa: de acordo com o Relatório do Desenvolvimento Humano (2015), o IDH dos Estados Unidos em 2014 era 0,915, já o IDHAD era 0,760 . Isso quer dizer que a desigualdade social e econômica do país faz com que o mesmo tenha uma perda de 17\%, caindo 20 posições na classificação do IDHAD. O Brasil, em 2014, apresentou IDH de 0,755 e IDHA de 0,557, tendo uma perda de $26,3 \%$ e caindo 20 posições na classificação do IDH. 
GARCIA-VILLEGAS, Mauricio. Normas de papel: La cultura del incumplimiento de reglas. Bogotá: Siglo del Hombre Editores S.A., 2009.

. Ineficacia del derecho y cultura del incumplimiento de reglas en América Latina. In: Garavito, César Rodríguez (org.). El derecho en América Latina: un mapa para el pensamiento jurídico del siglo XXI. Buenos Aires: Siglo Veintiuno Editores, 2011, pp. 161-184.

HABERMAS, Jürgen. Direito e Democracia: entre facticidade e validade. Vol. I. Rio de Janeiro: Tempo Brasileiro, 1997.

JACKSON, Jonathan et al. Why do people comply with the law? Legitimacy and the influence of legal institutions. British Journal of Criminology, 52 (6), 2002, p. 1051-1071.

. Developing European indicators of trust in justice. European Journal of Criminology, vol. 8, 2011, p. 267-285.

MOISÉS, José Álvaro. (org.) Democracia e Confiança - Por que os Cidadãos Desconfiam das Instituições Públicas? São Paulo: EDUSP, 2010.

O'DONNELL, Guilhermo. Poliarquias e a (in)Efetividade da Lei na América Latina. Novos Estudos Cebrap, vol. 51, 1998a, p. 37-61.

. Accountability horizontal e novas poliarquias. Lua Nova, São Paulo, n. 44, 1998b, p. 27-54.

ORGANIZAÇÃO DAS NAÇÕES UNIDAS. Relatório de Desenvolvimento Humano. Programa das Nações Unidas no Brasil, 2015.

SOUZA, Jesse. A sociologia dual de Roberto Da Matta: descobrindo nossos mistérios ou sistematizando nossos auto-enganos? Revista Brasileira de Ciências Sociais, v. 16, n. 45 , fev, 2001, p. 47-67.

TYLER, Tom. Why people obey the law? Princeton: Princeton University Press, 2006. Public Trust and Confidence in Legal Authorities: What Do Majority and Minority Group Members Want from the Law and Legal Institutions? Behavioral Sciences and the Law Behav. Sci. Law 19: 215-235 DOI: 10.1002/bsl.438, 2001.

VILHENA, Oscar Vieira. A desigualdade e a subversão do Estado de Direito. SUR: Revista Internacional de Direitos Humanos. São Paulo: Conectas. Ano 6, vol. 4, 2007, pp. 29 - 52. Disponível em: $\leq$ http://www.conectas.org/Arquivos/edicao/publicacoes/publicacao-201413116120296-22412338.pdf>. Acesso em: o6 out. 2017.

Recebido em 18/03/2017

Aprovado em 01/05/2017

\section{Como citar este artigo:}

OLIVEIRA, Fabiana Luci de; CUNHA, Luciana Gross. A legitimidade das leis e das instituições de justiça na visão dos brasileiros. Contemporânea - Revista de Sociologia da UFSCar, v. 7, n. 2, jul.- dez. 2017, pp. 275-296. 